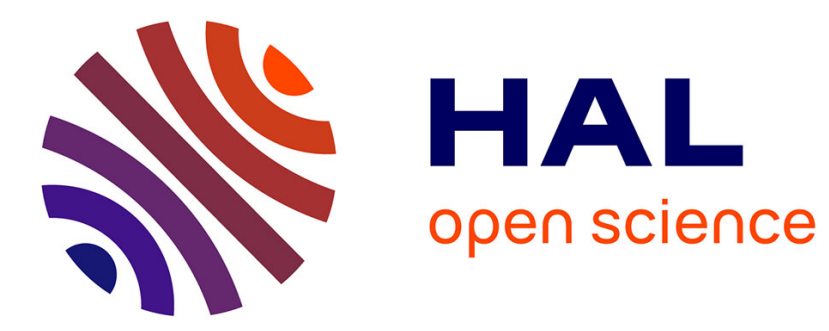

\title{
Impact resistance of composite materials under biaxal preloading
}

Christian Garnier, Toufik Djilali, Romain Brault, Sebastien Mistou

\section{To cite this version:}

Christian Garnier, Toufik Djilali, Romain Brault, Sebastien Mistou. Impact resistance of composite materials under biaxal preloading. Key Engineering Materials, 2011, vol. 482, pp. 39-48. 10.4028/www.scientific.net/KEM.482.39 . hal-00828347

\section{HAL Id: hal-00828347 \\ https://hal.science/hal-00828347}

Submitted on 30 May 2013

HAL is a multi-disciplinary open access archive for the deposit and dissemination of scientific research documents, whether they are published or not. The documents may come from teaching and research institutions in France or abroad, or from public or private research centers.
L'archive ouverte pluridisciplinaire HAL, est destinée au dépôt et à la diffusion de documents scientifiques de niveau recherche, publiés ou non, émanant des établissements d'enseignement et de recherche français ou étrangers, des laboratoires publics ou privés. 


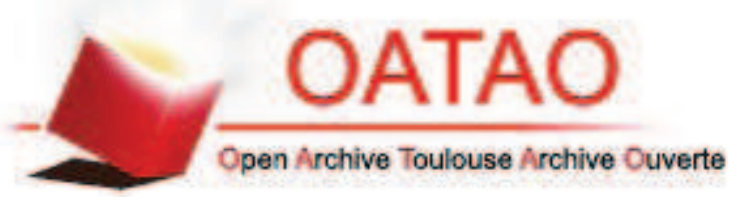

OATAO is an open access repository that collects the work of Toulouse researchers and makes it freely available over the web where possible.

This is an author-deposited version published in : http://oatao.univ-toulouse.fr/ Eprints ID : 8922

To link to this article : DOI: 10.4028/www.scientific.net/KEM.482.39

URL : http://dx.doi.org/10.4028/www.scientific.net/KEM.482.39

Open Archive TOULOUSE Archive Ouverte (OATAO)

To cite this version : Garnier, Christian and Djilali, Toufik and Brault, Romain and Mistou, Sebastien Impact resistance of composite materials under biaxal preloading. (2011) Key Engineering Materials, vol. 482 . pp. 39-48. ISSN 1013-9826)

Any correspondence concerning this service should be sent to the repository administrator: staff-oatao@listes.diff.inp-toulouse.fr 


\title{
Impact resistance of composite materials
}

\section{under biaxial preloading}

\author{
Christian GARNIER ${ }^{1, \text { a }}$, Toufik DJILALI ${ }^{2, b}$, \\ Romain BRAULT' ${ }^{2, c}$, Sébastien MISTOU ${ }^{1, d}$ \\ ${ }^{1}$ ENIT, 47 Avenue d'Azereix, BP 1629, 65016 Tarbes cedex, France \\ ${ }^{2}$ CRC Composites, 1 Rue Aristide Berges, 65016 TARBES Cedex, France
}

achristian.garnier@enit.fr, ${ }^{b}$ toufik.djilali@enit.fr, ${ }^{c}$ romain.brault@enit.fr, ${ }^{d}$ sebastien.mistou@enit.fr

Key words: Low-velocity impact, bi-axial preloading, composite, InfraRed Thermography, Sonoscan.

\begin{abstract}
The first aim of this study is to analyze the impact behavior of pre-loaded composite. Indeed, a bi-axial load is applied to the composite specimen, in order to keep in touch with a real case of composite fuselage. Then, this pre-loaded specimen is impacted by a pendulum. The used energy and velocity are weak in order to be in the case of low-energy and low-velocity impact.

The second aim of this study is to develop and design a pendulum device to be integrated to the biaxial fatigue loading. Moreover, two Non Destructive Inspections (Sonoscan and InfraRed Thermography) is used in order to establish links between pre-load and induced impact damage.
\end{abstract}

\section{Introduction}

Nowadays, impact on composite structures is a major problem in understanding its behavior. In flight or during maintenance, composite structures receive different specific impacts (birds impact, hail, or falling maintenance tools, ...) that can be classified along impact time or strain rate[1].

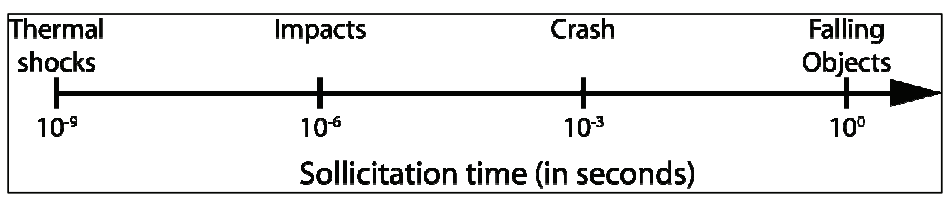

Fig 1: Classification of dynamics phenomena according to the sollicitation time [1]

\begin{tabular}{|c|c|c|c|}
\hline $\begin{array}{l}\text { Low- velocity } \\
\text { dynamics }\end{array}$ & & $\begin{array}{c}\text { medium-velocity } \\
\text { dynamics }\end{array}$ & $\begin{array}{l}\text { High-velocity } \\
\text { dynamics }\end{array}$ \\
\hline 1 & 10 & 100 & 1000 \\
\hline \multicolumn{4}{|c|}{ Strain speed (in s-1) } \\
\hline
\end{tabular}

Fig 2: Classification of dynamics phenomena according to the strain rate [1] 
During impact with a lower energy of BVID (Barely Visible Impact Damage), no surface damage are visible but damages may occur inside the structure (matrix crack, disbonding, ...)

Damages produced by a low-energy impact are specific to the structure and could be modified by using different materials or using a different way to impact the structure. Many parameters shall modify the size and the shape of the damaged area.

Previous studies [3.9] show the influence of fibers and matrices on the residual mechanical properties of impacted composite. The stacking sequence act on a large way on the size of the damaged area [4,6]. More the number of ply interfaces and the angle between two consecutive plies is important, less extended is the damage area. Other works perform that the curvature of the structure [7] or test conditions [2,9,10] act on the composite structure behaviour under impact.

In order to caraterize defects prodiced by impact loading, many Non Destructive Methods were developped and adapted to the composite materials ( Ultrasonic Testing, InfraRed Thermography, Shearography, X-Ray Tomography) [9-13].

However, the number of study about the influence of the pre-loading, on the size of the damaged area and on the residual mechanical properties, is low.

\section{Test device}

The test device realized to make this study is based on:

- Specific sample geometry

- Bi-axial fatigue machine

- An impact pendulum

- NDT devices

\section{Samples}

Samples used for this study are made from carbon fiber and epoxy resin. The prepreg process was implementing with a curing cycling under vacuum on oven. A new geometry was design. Indeed, theses specimens were tested in two steps. Firstly, the sample is mounted on the bi-axial machine in order to be impacted. Secondly, the sample is cut on to be tested in compression after impact (CAI). Another specificity of the sample is the high blend radius to avoid stress concentrations during the pre-loading.

The studied area is a $150 \times 100 \mathrm{~mm}^{2}$ center area with a constant section.

The thickness of the sample is $2 \mathrm{~mm}$.

Sample geometry is shown on Fig. 3.

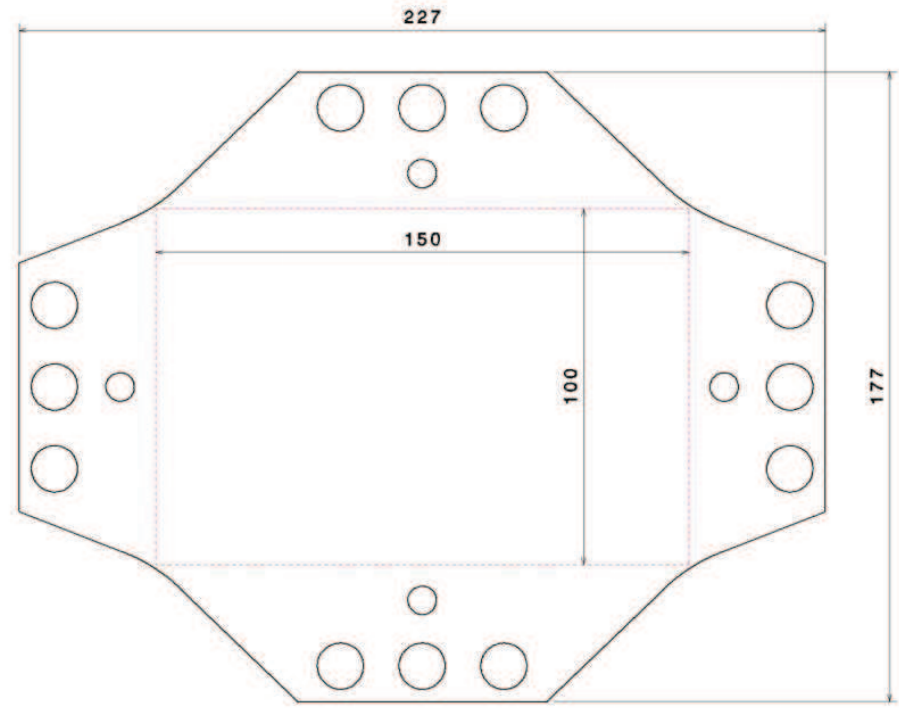

Fig 2. Sample geometry for bi-axial testing 


\section{Bi-axial machine}

The used device in order to apply the pre-loading to samples is an Instron $(8800$ bi-axial fatigue machine. It is composed of four cylinders. Two by two, the cylinders are the both axis of the machine. The capacity of each cylinder is $100 \mathrm{kN}$ in load. This device can apply static solicitations or dynamic ones with a low magnitude. The maximum frequency is $200 \mathrm{~Hz}$. Two by two, the cylinders can be driven in order to keep in position the center of the sample during tensile test. A large variety of test can be done driving cylinders one by one. This device is shown on the next figure (Fig. 4).

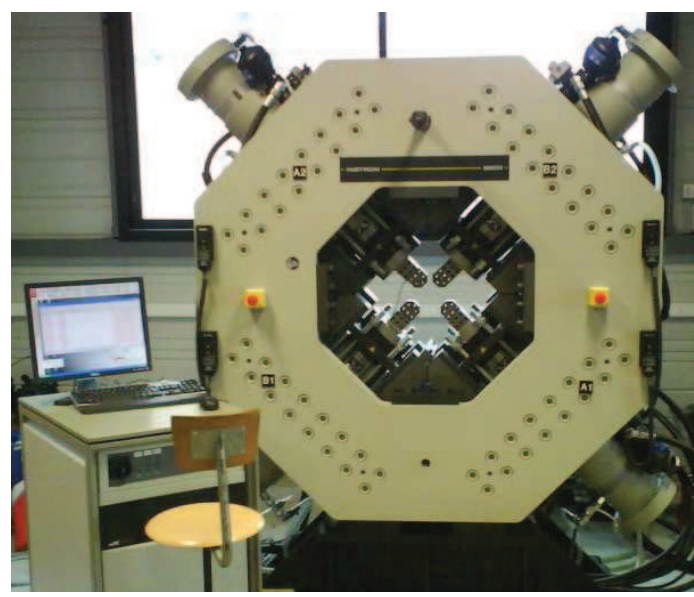

Figure 3 : Instron ${ }^{\circledR} 8800$ bi-axial fatigue machine

In this study, cylinders are driven both by both in order to keep the center of the sample fixed. This center is the location of the impact.

\section{Impact device}

This study deals with the impact response of pre-loaded composite structures. Commonly, a drop weight test machine is used to impact samples but in this case it is not possible. The second way, used in this study, is to design an impact device computed on the bi-axial test machine.

This device is a pendulum. It was design in order to impact the sample at its center. Note that the sample is already located in the bi-axial machine and the pre-loading is applied. The design of this devise is shown on Fig. 5.

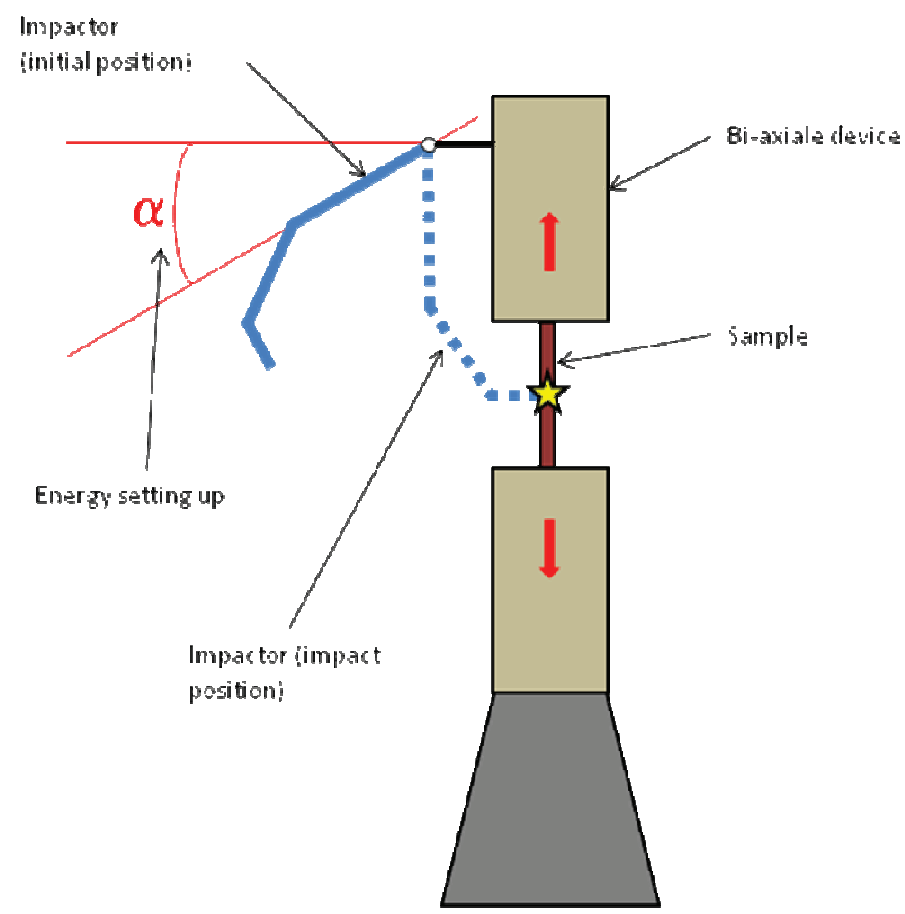

Figure 4 : Impact on pre-loading sample device 
The impact energy is regulated by modifying the $\theta$ angle. Two studies have been done to define the needed energy to obtain BVID. This energy is $10 \mathrm{~J}$, corresponding to a $3 \mathrm{~mm}$ depth defect. The first study is an energetic approach one; the pendulum is considered as a straight / rectilinear pendulum, without geometric discontinuity. The second study is an energetic approach: the pendulum is delimited in 5 parts of mass called mi.

These 2 approaches are built on an equation of mechanical energy for a single pendulum.

$$
\begin{gathered}
\mathrm{E}_{\mathrm{mi}}=\mathrm{E}_{\mathrm{pi}}=\mathrm{m}_{\mathrm{i}} \mathrm{gl}_{\mathrm{i}}\left(1-\cos \theta_{i}\right) \\
\sum_{i=1}^{5} E_{p i}
\end{gathered}
$$

Indeed, the falling pendulum angle $(\theta)$ is $8^{\circ}$ for a impact energy of $10 \mathrm{~J}$.

\section{Testing}

The following paragraphs describe the way to do and the procedure used to realize these tests. The results analysis is made by using different NDT ways/ methods. The aim of the NDT analysis of impacted specimen is to define the damage area inside the material.

So three NDT methods are used:

- IR thermography

- US detection

- X-rays tomography

The results obtained by the three methods are compared in order to define the most efficient, in coherence with pre charged impact study. And then, to perform future tests procedures.

\subsection{Testing procedures}

Specific procedure must be followed to realize these tests. Figure 6 is a chronological sequence of the steps for preloaded impact testing.

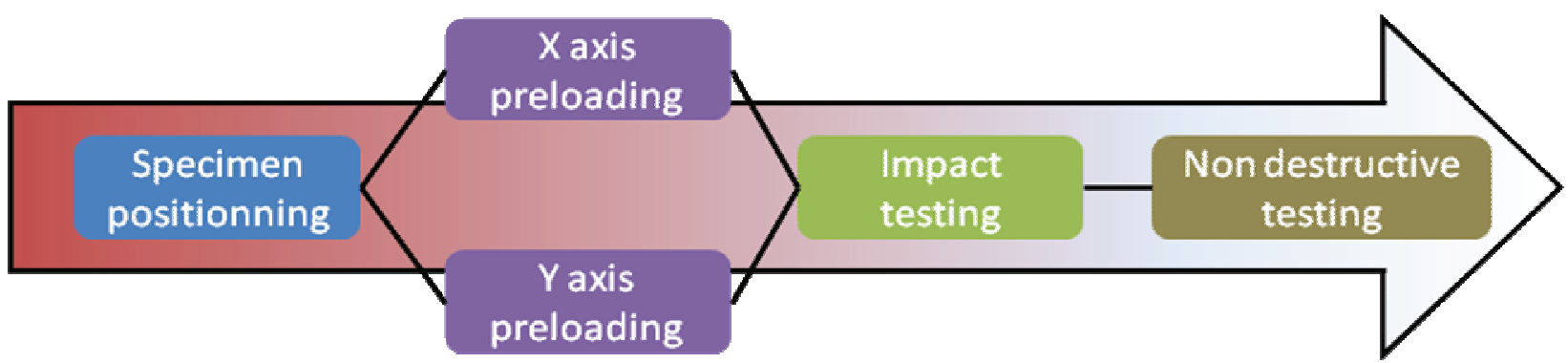

Figure 5 : Chronological sequence of the test

The specimen is located and fixed on the bi axial traction machine by a screwed assembly, which guarantee the adherence between specimen and each grip: any specimen slipping is avoid during the test.

The preload is a bi axial tension. This stress is not equal for the both axes of the cross shaped specimen. The aim of this preload is to simulate the pressurization state of a aeronautic structure during flight. To define the load to apply on the axis, the hypothesis is done that the fuselage can be considered as pipe under pressure, where a tangential stress $\sigma_{t}$ and a radial stress $\sigma_{r}$ are applied to the skin. The two stresses are calculated in function of pressure gradient $\mathrm{P}$ between outside and inside of fuselage, fuselage rayon $\mathrm{R}$ and skin thickness e, so : 


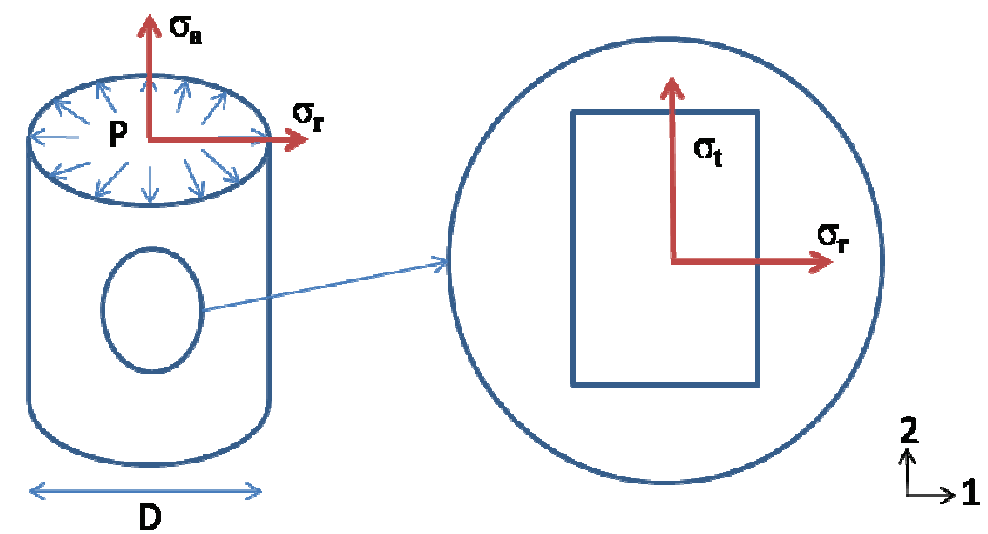

Figure 6 : Fuselage under pressure

$$
\begin{aligned}
& \sigma_{t}=\sigma_{a}=\frac{P R}{e} \\
& \sigma_{r}=\frac{P R}{2 e}
\end{aligned}
$$

The pressure gradient $\mathrm{P}$ is defined with standards which define pressuring tests for fuselages.

Table 1 : Measurements of the fuselage

\begin{tabular}{|c|c|c|c|c|c|c|}
\hline $\mathrm{L}_{1}(\mathrm{~mm})$ & $\mathrm{L}_{2}(\mathrm{~mm})$ & $\mathrm{e}(\mathrm{mm})$ & $\mathrm{P}(\mathrm{Mpa})$ & $\mathrm{R}(\mathrm{mm})$ & $\mathrm{S}_{1}\left(\mathrm{~mm}^{2}\right)$ & $\mathrm{S}_{2}\left(\mathrm{~mm}^{2}\right)$ \\
\hline 150 & 100 & 2 & 0,15 & 2600 & 300 & 200 \\
\hline
\end{tabular}

The loads to apply on cruciform specimen axis's are defined thanks to formula 1 and 2 (en function de) the sections in the both directions of the useful area of the sample :

$$
F_{i}=\sigma_{i} S_{i}
$$

So, loads to apply are obtained in the both directions.

Table 2 : Applied load

\begin{tabular}{|c|c|}
\hline $\mathbf{F}_{\mathbf{1}}(\mathbf{k N})$ & $\mathbf{F}_{\mathbf{2}}(\mathbf{k N})$ \\
\hline 15 & 20 \\
\hline
\end{tabular}

\subsection{NDT results}

Results analysis are done for damaged area because of impact on composite specimens. This damaged area can be analyzed in a quantitative way and precisely/in great precision thanks to the results obtained with US and IR thermography technologies. The result obtained is the projection of the damaged area of each ply on the surfaced measured by the sensor. Figure 8 and 9 are respectively pictures from US and thermo IR measurements. 


\subsubsection{IR thermography protocol}

Halogen lamps are used to provide thermal sollicitation to the sample. They are positioned 300 $\mathrm{mm}$ from the front surface of the specimen. The front surface has been chosen as being similar to an in-situ inspection. The specimen is heated for $10 \mathrm{~s}$, and a $30 \mathrm{~s}$ movie is recorded at $50 \mathrm{~Hz}$. The installation of the experimental device is very fast (around $5 \mathrm{~min}$ ). The camera is a Flir Titanium and its thermal resolution is $20 \mathrm{mK}$. In order to detect the defect present in the recording, a relative movie has been created. The relative movie consists of withdrawing the first ten images from the recorded film in order to eliminate the temperature due to the ambient environment. The presence of the defect appears during heating and cooling time. The defect is most visible in the image corresponding to the inflection point of the temperature curve. For the study, infrared images were taken at this point [13].
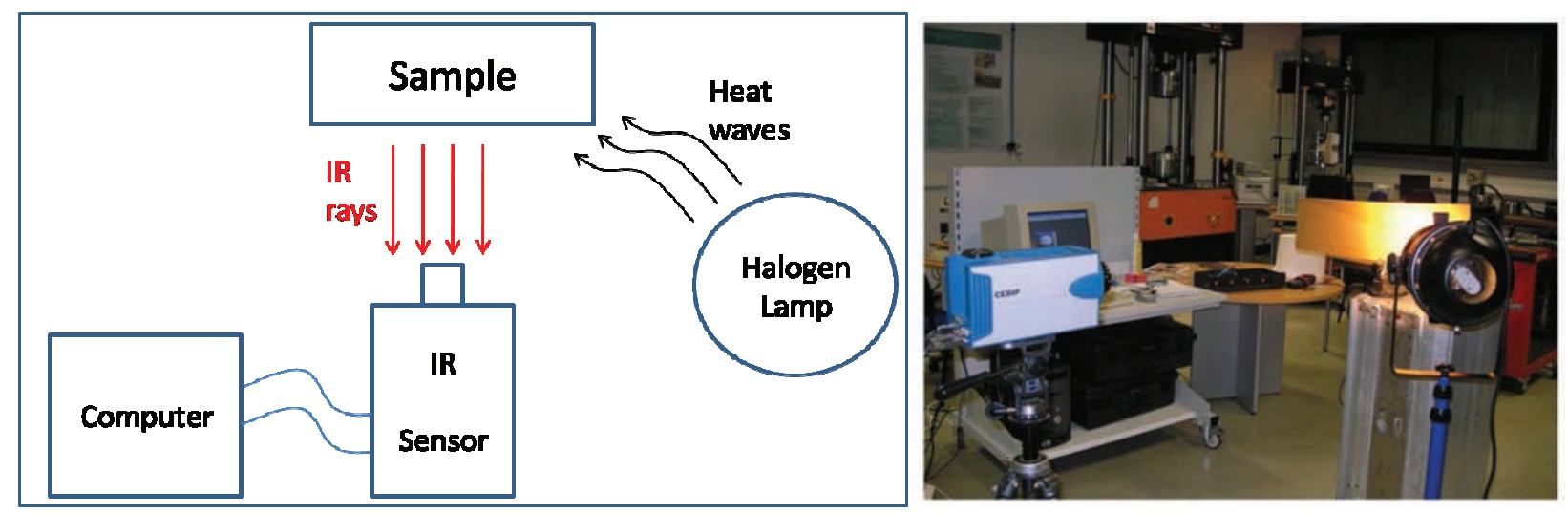

Figure 7 : IR thermography protocol [13]

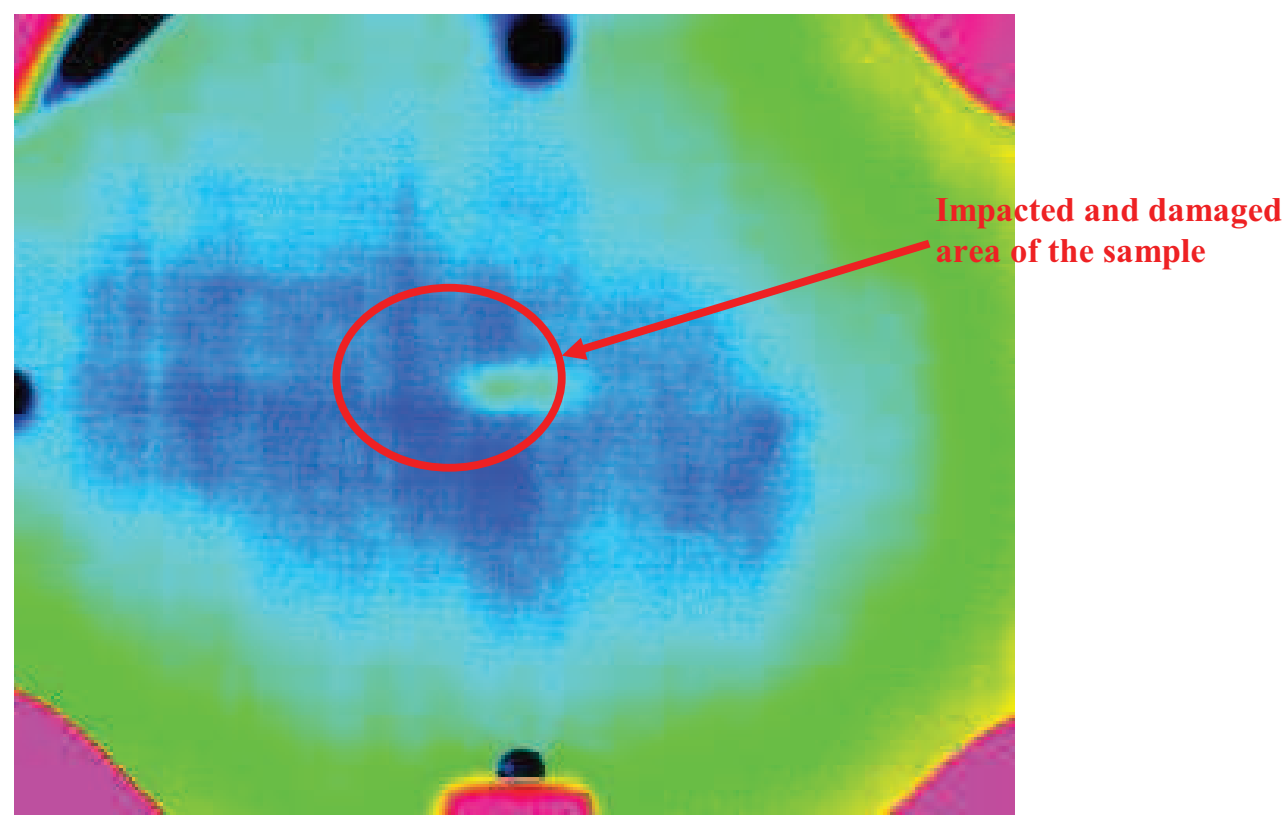

Figure 8: IR thermography 2D map of the damaged area 


\subsubsection{Sonoscan protocol}

In this study, a multi-element transducer connected to a Sonoscan (US monitor) is used as the ultrasonic source and the receiver. In order to carry out the experiments, the test is done in a pool and so the wave ratio transmitted to the sample is much better [13].

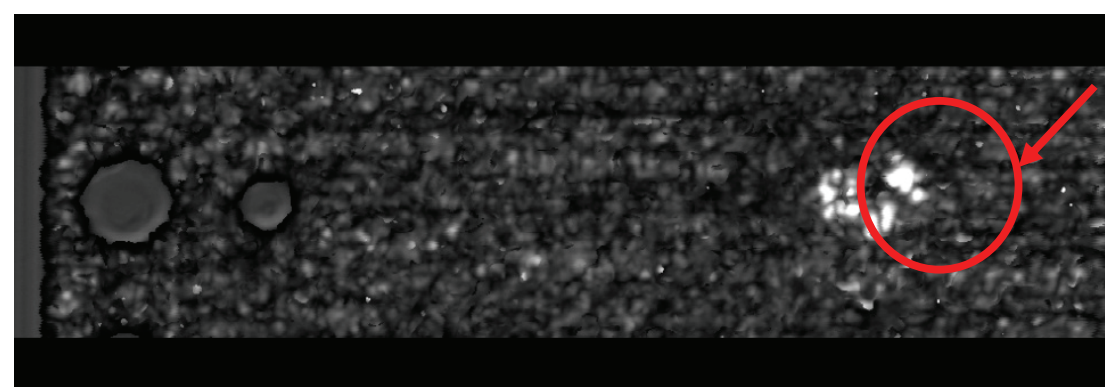

Impacted and damaged area of the sample

Figure 9 : Ultrasonic map of the damaged area

Following table 3 presents results obtained from measurement of DA (Damaged Area) on specimen pre-loaded or not, with US and thermographic measures. 


\begin{tabular}{|c|c|c|c|c|c|c|c|c|c|}
\hline & & Sample 2 & Sample 3 & Sample 4 & Sample 5 & Sample 6 & Sample 7 & Sample 8 & Sample 9 \\
\hline & Load direction $1(\mathrm{kN})$ & 15 & 15 & 15 & 30 & 30 & 30 & 0 & 0 \\
\hline & Load direction $2(\mathrm{kN})$ & 20 & 20 & 20 & 40 & 40 & 40 & 0 & 0 \\
\hline & Impact Energy ( $\mathrm{J}$ ) & 10 & 10 & 10 & 10 & 10 & 10 & 10 & 10 \\
\hline & Dent depth ( mm) & 0,3 & 0,3 & 0,28 & 0,33 & 0,32 & 0,4 & 0,45 & 0,27 \\
\hline \multirow{5}{*}{ 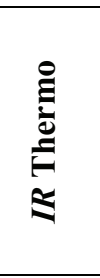 } & Shape oft he damaged area ( $D A)$ & elliptic & circular & circular & elliptic & elliptic & elliptic & circular & Elliptic \\
\hline & Direction of the $D A$ & 2 & 1 & 1 & 2 & 1 & 2 & 1 & 2 \\
\hline & Length of the DA on the direction $1(\mathrm{~mm})$ & 8 & 14 & 13 & 9 & 19 & 13,5 & 13 & 11 \\
\hline & Width of the $D A$ in the direction $2(\mathrm{~mm})$ & 22 & 14 & 14 & 20 & 11 & 17 & 13,5 & 16 \\
\hline & Size of the DA $\left(\mathrm{mm}^{2}\right)$ & 138,2 & 153,9 & 142,9 & 141,4 & 164,1 & 180,2 & 137,8 & 138,2 \\
\hline \multirow{6}{*}{ 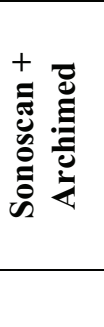 } & Shape oft he damaged area $(D A)$ & elliptic & elliptic & circular & elliptic & elliptic & elliptic & elliptic & elliptic \\
\hline & Direction of the $D A$ & 2 & 1 & 1 & 2 & 1 & 2 & 1 & 2 \\
\hline & Length of the DA on the direction $1(\mathrm{~mm})$ & 9,5 & 10,5 & 14 & 10 & 20 & 13,5 & 13,46 & 12,5 \\
\hline & Width of the DA in the direction $2(\mathrm{~mm})$ & 15,5 & 6,7 & 13,5 & 16 & 11,5 & 16 & 15,68 & 14,5 \\
\hline & Size of the $D A\left(\mathrm{~mm}^{2}\right)$ & 115,6 & 55,3 & 148,4 & 125,7 & 180,6 & 169,6 & 165,8 & 142,4 \\
\hline & Gap between IR Thermography and Sonoscan & 16,3 & 64,1 & 3,8 & 11,1 & 10,0 & 5,9 & 20,2 & 3,0 \\
\hline
\end{tabular}

Tableau 3 : NDT results for preloaded samples 
Table 4 : NDT results for non-loaded samples

\begin{tabular}{|c|c|c|c|}
\hline & Sample 1.3 & Sample 2.1 & Sample 2.2 \\
\hline Load direction $1(\mathrm{kN})$ & 0 & 0 & 0 \\
\hline Load direction $2(\mathrm{kN})$ & 0 & 0 & 0 \\
\hline Impact Energy ( J ) & 10 & 10 & 10 \\
\hline Dent depth ( $\mathrm{mm})$ & 0,56 & 0,49 & 0,56 \\
\hline Shape oft he damaged area $(D A)$ & elliptic & elliptic & elliptic \\
\hline Direction of the $D A$ & 2 & 2 & 2 \\
\hline Length of the $D A$ on the direction $1(\mathrm{~mm})$ & 14 & 13,5 & 15,5 \\
\hline Width of the $D A$ in the direction $2(\mathrm{~mm})$ & 18 & 15 & 20 \\
\hline Size of the $D A\left(\mathrm{~mm}^{2}\right)$ & 197,9 & 159,0 & 243,5 \\
\hline
\end{tabular}

From these measurements, sonoscan and IR thermography supply similar results, such in a qualitative than in a quantitative point of view (absolute error values between the two measurements nearly always under or equal to $15 \%$ ).

Furthermore, the comparison between specimens loaded and unloaded allow to deduce that the preload increase the DA. This preload acts only on the DA size, but not on its shape.

One of the future ways to define the DA is X-ray Tomography.

$\mathrm{X}$-ray tomography technique has been used to evaluate the potential in the composite defect study. This technique is a way to conduct an internal analysis of materials. Indeed, by an X-ray beam through a sample in a high number of positions, a 2D reconstruction showing the section of a slice $(0.3 \mathrm{~mm}$ thick) of sample was performed for all measured positions (see Figure 2). The image sequence thus obtained represents the different sections reconstructed over the entire sample. These grayscale images reflect the differences in X-ray attenuation by the internal structure of the sample measured in function of difference of density. Any defect or damage is directly visualized on tomographic sections through the density contrast between these defects and material. This technique allows a 3D analysis. Moreover it is a very powerful tool for studying the internal behavior of materials after damage [14].

So the X-rays tomography tests have been used during this study to visualize qualitatively damage. Figure 10 represents two views in different cutting planes of an impacted specimen.
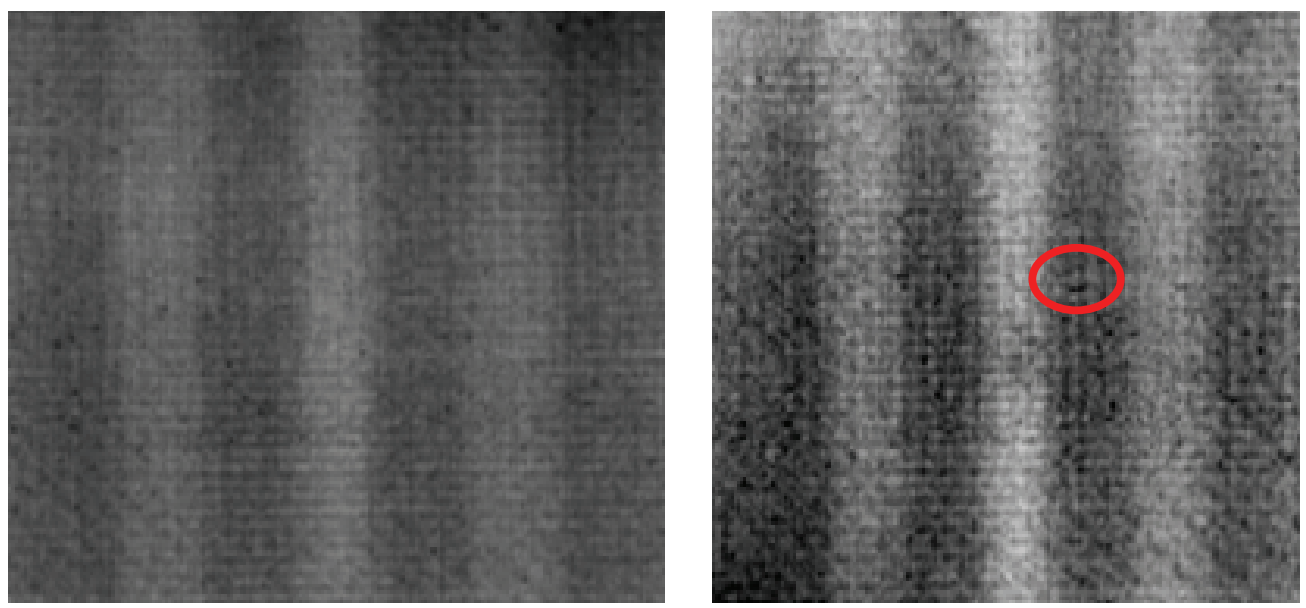

Figure $10:$ X-ray tomography results

Then, a deeper analysis of these results could make possible an accurate determination of the DA size, and its three dimensions reconstruction to access to a better understanding of the impact damage after impact under pre-loading. 


\section{Conclusions}

This study presents a comparison of damaged area on preloaded and not preload impacted specimen. Several NDT have been used. We conclude that :

- US and IR thermography are similar for defects detection

- Preloading increases the size of damaged area

- X-rays tomography approach gives more information of three dimensions damaged area

This study is only a start point to understand mechanical behaviour of preloaded structures. The identification of the damaged area is validate by using new methods. A next study will deal with residual mechanical properties of these specimens.

\section{References}

[1] A. Dragon, Mécaniques et industries (2000) 521-537

[2] E. Demuts, R. S. Sandhu, J.A. Daniels, report N DOT/FAA/CT-92-25 (1992) 1097 - 1104.

[3] D.D.R. Cartié, P.E. Irving, Comp. part A 33 (2002) 483 - 493.

[4] S.A. Hitchen and R.M. Kemp, Comp. 26 (1994) 207-214.

[5] E. Fuoss, P.V.Straznicky, C. Poon, Comp. Struc. 41 ( 1998 ) 67 -77.

[6] D.R. Ambur and J.H. Starnes Jr, In structures, structural dynamics, and material conference (1998).

[7] H.P. Kan, Final report DOT/FAA/AR-97/79 (1998).

[8] T. Mitrevski, I.H. Marshal, R. Thomson, R. Jones and B. Whittingham,, comp. struct. (2004).

[9] A. BIRK, R. GREEN, Nondestructive Testing Handbook, volume 7: Ultrasonic Testing, 2 edition, 1991.

[10] Gros XE, Bousigue J, Takahashi K. NDT data fusion at pixel level. NDT \& E Int 1999;32(5):283-292.

[11] Vary A. Acousto-Ultrasonics, In: Nondestructive testing of fiber reinforced plastics. Composites 1990;2:1-54.

[12] Chrysochoos A. Infrared thermography, a potential tool for analysing the material behaviour. Méca \& Indust 2002;3: 3-14.

[13] Garnier C., Pastor M-L., Eyma F., Lorrain B. The detection of aeronautical defects in situ on composite structures using Non Destructive Testing, Comp Struc, Vol 93, Issue 5, April 2011, pp. $1328-1336$

[14] Schilling P.J., Karedla B.R., Tatiparthi A.K., Verges M.A., Herrington P.D., Comp. Sc. \& Tech. 65, 2071-2078 (2005) 